\title{
A experiência turística nas redes sociais: Motivações, implicações e impactes da geração de conteúdos
}

\section{The touristic experience in social networks: Motivations, implications and impacts of content generation}

\author{
Nuno M.B. Antunes \\ Mestrado em Marketing Turístico, Universidade do Algarve, Portugal \\ nunantunes@gmail.com
}

Célia M.Q. Ramos

Escola Superior de Gestão, Hotelaria e Turismo e CIEO, Universidade do Algarve, Portugal cmramos@ualg.pt

Carlos M.R. Sousa

Escola Superior de Gestão, Hotelaria e Turismo, Universidade do Algarve, Portugal cmsousa@ualg.pt

\section{Resumo}

O presente estudo pretende identificar e caraterizar padrões de comportamento dos turistas nas social media durante e após as suas viagens, averiguando o que leva os turistas a gerar conteúdos nas social media. Para tal, procedeu-se à contextualização teórica acompanhada por um levantamento de dados primários obtidos através de um inquérito aplicado aos turistas portugueses que viajaram em 2014 e/ou 2015, e analisados utilizando estatística descritiva e tabulação cruzada. Os resultados apontam para o facto de as plataformas de social media mais utilizadas serem as redes sociais, que as principais motivações para a autoexpressão nas social media derivam da qualidade da própria experiência, enquanto nos websites de reviews, as avaliações são feitas independentemente da qualidade da experiência em causa.

Palavras-chave: Conteúdo gerado pelo utilizador; experiência turística; Internet; redes sociais; social media; websites de reviews.

\begin{abstract}
This study aims to identify and characterize behavioural patterns displayed by tourists on social media platforms during and after their holiday, in particular the motivations for tourists to share their experience online. To explore this, following a theoretical contextualization primary data was collected through a questionnaire survey, which was applied to Portuguese tourists who travelled in 2014 and/or 2015. The data was then analyzed using descriptive statistics and cross-tabulation. The results allow us to conclude that the most frequently used social media platforms are social networks, the main motivations for self-expression on social networks are connected to the quality of the experience itself, while on the review websites, the reviews are made regardless of the quality of the experience in question.
\end{abstract}

Keywords: Internet; review websites; social media; social networks; tourist experience; usergenerated content.

Dos Algarves: A Multidisciplinary e-Journal, $32-2018$

ISBN 2182-5580 @ ESGHT - University of the Algarve, Portugal.

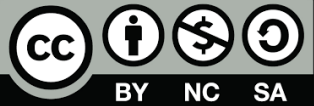

To cite this article: Antunes, N.M.B., Ramos, C.M.Q. \& Sousa, C.M.R. (2018). A experiência turística nas redes sociais: Motivações, implicações e impactes da geração de conteúdos. Dos Algarves: A Multidisciplinary e-Journal, 32, 20-37. doi: 10.18089/DAMeJ.2018.32.2 


\section{Introdução}

Os avanços tecnológicos têm afetado a vida humana de inúmeras formas, sendo uma delas o modo como se acede à informação. $O$ franco crescimento das tecnologias de informação e comunicação (TIC) e a facilidade de acesso à Internet trouxeram à sociedade novos meios de interação e coexistência (Damian, 2014), disponíveis em plataformas como as redes sociais, os blogues pessoais, websites de partilha de multimédia (como o YouTube e o Flickr), comunidades online, entre outros (Xiang \& Gretzel, 2010). Esta realidade obrigou a que os marketeers passassem a ponderar uma nova forma de comunicação: o Marketing Digital, focado no direcionamento de esforços de marketing no sentido de se conectarem com o vastíssimo número de consumidores constantemente presente online (Damian, 2014; Ryan, 2014).

Paralelamente, é um facto que a evolução das TIC influência diretamente a indústria turística, dada a natureza do próprio produto turístico, o qual, entre outras caraterísticas, é intangível e requer que a compra seja efetuada num espaço de tempo significativamente prévio ao consumo (Buhalis \& Law, 2008). Isto leva a que o consumidor procure informar-se ao máximo sobre o produto turístico, o que fundamenta a elevada importância da informação nesta indústria.

Os autores Pan, MacLaurin e Crotts, (2007), Carrera, Chiu, Pratipwattanawong, Chienwattanasuk, Ahmad e Murphy (2008), Litvin, Goldsmith e Pan (2008), Yoo e Gretzel (2008a), Yoo e Gretzel (2008b), Yoo e Gretzel (2008c), Gretzel, Lee, Tussyadiah e Fesenmaier (2009), Yoo, Lee e Gretzel (2009), Yoo, Lee, Gretzel e Fesenmaier (2009), Xiang e Gretzel (2010), Fotis (2015) e Yoo e Gretzel (2012) constatam que uma porção cada vez maior dos conteúdos de turismo disponíveis na Internet provém dos próprios turistas. Ao mesmo tempo, os conteúdos gerados por outros consumidores são cada vez mais procurados para apoiar o planeamento da viagem de turistas prospetivos (Buhalis \& Law, 2008; O'Connor, 2008; Adjei, Noble \& Noble, 2010; Xiang \& Gretzel, 2010; Munar \& Jacobsen, 2014; Fotis, 2015).

Neste âmbito, as social media, fonte de manifesta abrangência de conteúdos turísticos gerados por consumidores, são o foco deste estudo, que pretende contribuir com uma análise aprofundada do comportamento do turista enquanto criador de conteúdos na Internet.

A fim de atingir o objetivo identificado, a investigação divide-se em quatro secções complementares para além da presente introdução. A primeira secção da revisão da literatura pretende identificar, descrever e fundamentar devidamente as problemáticas principais que rodeiam o estudo do comportamento do turista nas social media. A secção da metodologia descreve os procedimentos adotados ao longo da aferição de resultados com base nos dados empíricos obtidos por via de inquérito, desde a escolha do método de obtenção de dados, até aos processos estatísticos utilizados para análise dos mesmos. A secção da análise efetuada sobre os dados empíricos inclui os resultados apurados estatisticamente. Por fim, a última secção, apresenta as conclusões da investigação efetuada.

\section{Revisão da literatura}

\subsection{A experiência turística}

O turismo é uma indústria de experiências, pois não se vende um produto específico nem um serviço específico, mas sim o somatório das diversas experiências que o turista poderá viver 
nos "palcos" (termo cunhado por Pine e Gilmore em 1998 para descrever o conjunto de produtos e serviços que formam o ambiente da experiência) construídos pelo destino.

O termo "experiência" não tem uma definição universalmente aceite (Mannell \& IsoAhola, 1987; Carù \& Cova, 2003; Gentile, Spiller \& Noci, 2007; Huang \& Hsu, 2009; Tung \& Ritchie, 2011). Tung e Ritche (2011) expressam a sua preocupação face à ausência de acordo aquando da construção de uma definição compreensiva de "experiência turística". Segundo Matos (2014), para muitos autores, o termo permanece demasiado ambíguo, enquanto que, para outros, a sua complexidade é o que o torna difícil de definir, identificar e operacionalizar.

Ainda assim, alguns investigadores identificam certas convenções, as quais Matos (2014), reúne e sumariza (ver Tabela 1).

Tabela 1. Definições de experiência turística

\begin{tabular}{|c|c|}
\hline Referência & Definição \\
\hline Holbrook \& & \\
\hline $\begin{array}{l}\text { Hirschman } \\
(1982: 132)\end{array}$ & "A steady flow of fantasies, feelings, and fun". \\
\hline $\begin{array}{l}\text { Otto \& Ritchie } \\
(1996: 166)\end{array}$ & $\begin{array}{l}\text { "The 'experience' of leisure and tourism can be described as the } \\
\text { subjective mental state felt by participants". }\end{array}$ \\
\hline $\begin{array}{l}\text { Pine \& Gilmore } \\
\text { (1998: 98) }\end{array}$ & $\begin{array}{l}\text { "An experience occurs when a company intentionally uses services } \\
\text { as the stage, and goods as props, to engage individual customers in } \\
\text { a way that creates a memorable event" }\end{array}$ \\
\hline $\begin{array}{l}\text { Schmitt } \\
(1999: 25)\end{array}$ & $\begin{array}{l}\text { The "result of encountering, undergoing, or living through } \\
\text { situations" and "triggered stimulations to the senses, the heart, and } \\
\text { the mind". }\end{array}$ \\
\hline $\begin{array}{l}\text { Bigné \& Andreu } \\
(2004: 692)\end{array}$ & $\begin{array}{l}\text { "Experiences can be defined as events that engage individuals in a } \\
\text { personal way". }\end{array}$ \\
\hline $\begin{array}{l}\text { Volo } \\
\text { (2010: 301) }\end{array}$ & $\begin{array}{l}\text { "The tourist experience is defined as an occurrence experienced by } \\
\text { a person outside the 'usual environment' and the 'contracted time' } \\
\text { boundaries that is comprised of a 'sequence' of the following } \\
\text { events: sensation, perception, interpretation, and learning". }\end{array}$ \\
\hline
\end{tabular}

Fonte: A partir de Matos (2014: 46-47).

De modo a garantir uma definição objetiva e universalmente aplicável para efeitos do presente estudo, propõe-se que seja considerado "elemento da experiência turística" qualquer acontecimento, produto ou serviço que advenha da viagem turística associada, independentemente do seu posicionamento no espaço e no tempo, e que seja passível de ser identificado pelo próprio turista.

No que concerne à última parte desta proposta definitória, referente à identificabilidade do elemento da experiência pelo turista, verifica-se que não estão incluídas, portanto, ações a nível estratégico no destino, como atividades administrativas e outras iniciativas de gestão que, apesar de afetarem a indústria turística a uma escala macro, não são diretamente percecionadas pelo turista. Esta restrição é feita devido à necessidade de incluir apenas os fatores claros do ponto de vista do turista na sua viagem, dado que o presente estudo incide sobre a experiência do consumidor; inclusivamente, Pine e Gilmore (1998), Oh, Fiore e Jeoung (2007) e Matos (2014) referem que a experiência é um fenómeno que existe exclusivamente na mente do consumidor, o qual é submetido a interações de diferentes tipos - físicas, emocionais ou intelectuais, por exemplo - criando uma experiência 
inerentemente pessoal. Por outras palavras, não será possível identificar uma experiência turística sem que haja a participação de turistas.

A experiência compreende, portanto, os momentos de pesquisa feitos previamente à compra da experiência turística, interações com sistemas de reserva ou prestadores de serviços similares, momentos de transporte para/no/do destino turístico, usufruto de produtos ou serviços na unidade de alojamento e no destino turístico em geral, participação em atividades de animação e eventos no destino, interações com profissionais de turismo, residentes e outros turistas e ainda interações com atrativos turísticos do destino como monumentos, espaços de lazer, entre outros.

Partindo mais especificamente para o estudo do consumo da experiência turística, de acordo com Quan e Wang (2004), Uriely (2005) e Matos (2014), as experiências turísticas podem ser encaradas do ponto de vista das ciências sociais, as quais consideram as atrações turísticas e as experiências que estas permitem que o consumidor viva como o principal incentivo para a viagem turística. Por outro lado, podem ser observadas numa perspetiva de marketing com enfoque no consumidor.

Com base nesta última perspetiva, mais relevante para a presente investigação, uma vez que centrada no comportamento do consumidor, Matos (2014) e Pine e Gilmore (2011) defendem que, anteriormente, os consumidores - logo, os turistas - eram vistos como seres racionais e a aquisição de bens e serviços era o resultado de uma análise racional. Porém, ainda segundo os autores, esta visão tem vindo a mudar recentemente, à medida que os especialistas de marketing se têm vindo a aperceber de que os bens e serviços são comprados, não apenas pelas vantagens que trazem ao consumidor, mas também pelo que representam. Esta realidade reforça a importância de construir experiências associadas a um produto ou serviço, para que o consumidor acrescente um valor subjetivo, mas não menos precioso, àquilo que consome.

A perceção que o turista terá sobre a experiência turística surgirá de forma natural. Ora a experiência é positiva (o desenlace mais desejado, tanto pelo turista como pelos profissionais de turismo), se corresponder ou superar as suas expetativas, ou é negativa, se o balanço dos vários elementos da experiência for inferior ao que o turista esperava. Em ambos os casos, os efeitos da experiência sobre o consumidor far-se-ão sentir num plano subjetivo e intangível, sendo o resultado tão memorável quanto intenso.

Como Gunn (1988) explica, o desenlace da experiência e as sensações evocadas ficam com o turista depois da viagem. Em casa, quando este reflete sobre as experiências turísticas que viveu, essas sensações irão influenciar fortemente a sua perceção sobre o destino. Simultaneamente, as mesmas sensações terão uma influência igualmente forte sobre a forma como o turista transmite as experiências que viveu a terceiros, seja em conversa com familiares ou amigos, seja no momento de relatar a experiência nas redes sociais e nos websites em que se publicam reviews, como o TripAdvisor e a Booking (Kim, Ritchie \& McCormick, 2012; Munar \& Jacobsen, 2014; Andrades, Dimanche, Prebensen, Chen \& Uysal, 2014).

\subsection{Social media}

As social media (em português, media sociais) representam uma evolução na forma de comunicar da humanidade. A universalização das TIC como plataforma de interação social foi 
possível dadas as caraterísticas natas das social media mais proeminentes, que beneficiam de uma enorme facilidade de uso, da oferta de ferramentas de partilha de diferentes tipos de conteúdo (multimédia, texto, hiperligações, entre outros) e do próprio facto de este meio de comunicação superar barreiras físicas, permitindo interação de pessoas em espaços e tempos diferentes.

2.2.1. Conceito de social media - à semelhança do que se observa relativamente à definição de experiência turística, a definição de social media também se tem provado difícil de concretizar (Yoo \& Gretzel, 2010; Yoo \& Gretzel, 2011; Munar \& Jacobsen, 2014; Ryan, 2014; Fotis, 2015).

Para Munar e Jacobsen (2014), as social media são um termo que abrange vários tipos de plataformas online, entre os quais se destacam alguns dos mais populares, como wikis (Wikitravel), blogues (Travelblog), microblogues (Twitter), redes sociais (Facebook), websites de partilha de multimédia (YouTube, Flickr, Instagram) e websites de reviews (TripAdvisor). Fotis (2015) apoia esta definição, esclarecendo que social media será um termo que abrange todas as aplicações online cuja função principal é o desenvolvimento e troca de conteúdos gerados pelo utilizador (UGC - User Generated Content). O autor nota que esta definição não inclui plataformas em que a troca de UGC serve um propósito secundário, como é o caso do website da Booking, que desempenha uma função primariamente comercial e permite troca de UGC como acessório ao comércio.

Não obstante, e tendo em consideração a definição de Fotis (2015), neste estudo optouse por incluir websites em que a troca de UGC serve um propósito secundário na definição do termo social media. Esta inclusão vem por conveniência de agregar o TripAdvisor (que se encaixa no termo social media original do autor) com semelhantes websites em que os consumidores produzam reviews (como é o caso da Booking), visto que o turista utilizará as ferramentas de geração de conteúdos independentemente de estas serem o propósito primário da plataforma ou não. Efetivamente, esta definição permite uma maior abrangência das possíveis plataformas onde o turista produzirá ou consumirá UGC, que são o foco do estudo.

Em português, a expressão "rede social" é usada como termo generalista para se referir a social media, ou seja, a generalidade das plataformas sociais na Internet. No entanto, o Facebook, por exemplo, desempenha em específico o papel de rede social (social network) por se focar na união de indivíduos através da Internet, criando uma rede digital unida pelos relacionamentos reais que as pessoas têm entre si (Kaplan \& Haenlein, 2010; Fotis, 2015; Facebook, 2017). Como tal, ao longo deste artigo, continuará a ser utilizado o termo social media acima descrito, bem como o termo "rede social", separadamente.

2.2.2. As social media hoje - as social media têm revelado um franco crescimento, não só de funcionalidades, mas também de utilizadores. O Facebook, fundado no início de 2004, possui, em média, cerca de 2100 milhões de utilizadores únicos ativos por mês (Facebook, 2017). O Twitter conta com 330 milhões (Twitter, 2017), o TripAdvisor soma 455 milhões (TripAdvisor, 2017) e o Instagram mais de 700 milhões de utilizadores únicos ativos por mês (Instagram, 2017). Estes números são indicativos claros da relevância que as social media têm atualmente, 
na medida em que são utilizadas por uma percentagem muito significativa da população mundial.

O Facebook, com um número de utilizadores incomparavelmente superior às demais plataformas, marca uma posição inquestionável enquanto espaço (digital) de partilha e comunicação para a sociedade. Por outro lado, o grande alcance das social media veio trazer novas formas de os consumidores interagirem com as empresas. No que se refere ao turismo, este impacte foi extremamente significativo, devido à necessidade de informação abundante e confiável. É para este fim que se usam as social media no âmbito do turismo, servindo de ferramenta de partilha de opiniões e experiências e criando conteúdos credíveis (testemunhos), que podem ser partilhados com quem o utilizador pretender.

2.2.3. Social media no turismo - em 2013, num estudo elaborado pela TNS Political \& Social (2013), turistas europeus foram inquiridos a propósito das fontes de informação que consideram mais importantes para a tomada de decisão acerca do seu plano de viagem. Dos inquiridos, 56\% mencionaram "recomendações de amigos, colegas ou familiares" e $46 \%$ mencionaram "websites na Internet". No entanto, apenas $5 \%$ assinalaram "social media sites" como uma fonte de informação importante. Este número pode ser interpretado como um indicativo de que as redes sociais, podendo despertar o interesse em determinado destino turístico, não são descritivas o suficiente para impactar notoriamente a tomada de decisão. Por outro lado, esta baixa percentagem pode ser consequência da dissociação entre redes sociais (como o Facebook e o Instagram, que poderão ser pouco influentes na tomada de decisão) e as restantes formas de social media (como o TripAdvisor, vídeos no YouTube e blogues, entre outros, que já terão maior participação na tomada de decisão), sendo que estes últimos poderão ter sido considerados simplesmente "websites na Internet" pela maioria dos inquiridos.

Na realidade, uma porção cada vez maior dos conteúdos de turismo disponíveis na Internet provém dos próprios turistas, representando esta uma fonte de informação extremamente valiosa tanto para os consumidores como para os profissionais de turismo (Pan et al., 2007; Carrera et al., 2008; Litvin et al., 2008; Yoo \& Gretzel, 2008a; Yoo \& Gretzel, 2008b; Yoo \& Gretzel, 2008c; Gretzel et al., 2009; Yoo et al., 2009; Xiang \& Gretzel, 2010; Fotis, 2015; Yoo \& Gretzel, 2012).

Citando Yoo e Gretzel (2016: 192), "It is obvious that social media provide a fertile venue for travellers to create and share their travel experiences and also take on an important role in tourist information search and decision-making.". Esta realidade torna fundamental a compreensão do uso que é feito das social media em prol da viagem turística, bem como das motivações e fatores que contribuem para a interação existente nestas plataformas de partilha de conteúdos.

Para melhor compreender esta temática, Fotis (2015) implementou um estudo qualitativo por entrevista semiestruturada, com base no qual identificou quatro formas de utilizar as social media no âmbito da viagem turística (antes, durante e após a viagem): (1) enquanto fonte de informação que ajuda à tomada de decisão; (2) enquanto plataforma de autoexpressão; (3) enquanto ferramenta de colaboração com os restantes intervenientes na viagem; (4) enquanto ferramenta de entretenimento durante a viagem. 
Figura 1. Fatores que motivam a autoexpressão do turista nas redes sociais

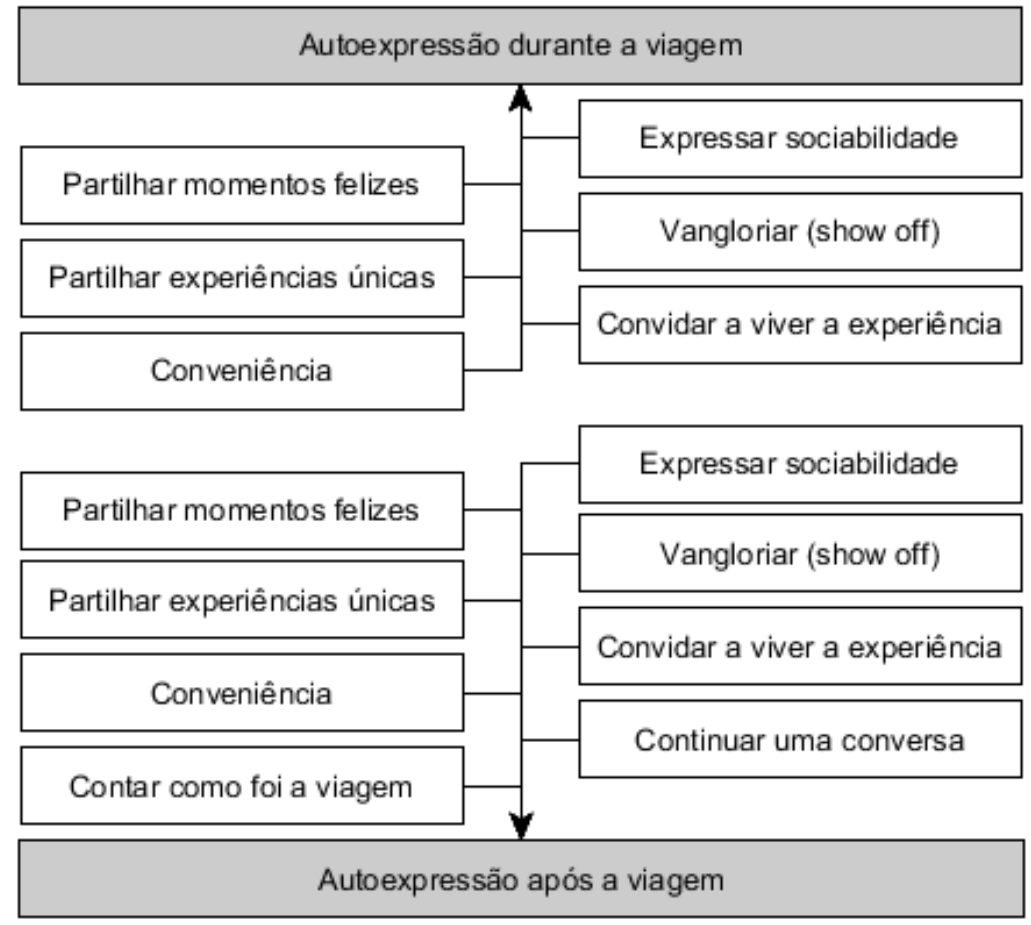

Fonte: A partir de Fotis (2015: 293).

Focando o caso das motivações que levam à autoexpressão por parte do turista nas redes sociais, Fotis (2015) identifica seis fatores que se aplicam tanto a durante como após a viagem, mais dois específicos para após a viagem (ver Figura 1).

$\mathrm{Na}$ lista que se segue, descrevem-se as motivações para a autoexpressão durante a viagem, as quais são medidas com o inquérito do presente estudo e, posteriormente, analisados.

- Conveniência: o facto de a partilha de experiências nas redes sociais ser uma forma de autoexpressão fácil e acessível que, convenientemente, também funciona como forma de armazenamento de conteúdos (na Internet);

- Show-off: o facto de agradar ao turista a ideia de que os seus contactos querem fazer o que ele está a fazer;

- Partilhar experiências únicas: o facto de certas experiências serem tão inéditas que merecem ser contadas;

- Convidar outros a viver a experiência: o desejo de recomendar aos seus contactos o consumo de determinadas experiências;

- Partilhar momentos felizes: a intenção do turista em partilhar com os seus contactos os momentos da viagem que o deixam sumamente feliz;

- Expressar sociabilidade: o facto de a partilha de conteúdos da viagem ser um ato socialmente expectável e ser desejável para o turista mostrar conformidade com esta norma social.

Em resumo, as social media são um meio por excelência para os consumidores expressarem as suas opiniões no meio digital sobre as suas experiências e para os destinos turísticos analisarem a opinião dos seus consumidores, os turistas. Neste contexto, o objetivo 
da presente investigação é o de contribuir para a análise do comportamento do turista enquanto criador de conteúdos na Internet.

\section{Metodologia}

Para responder às problemáticas apresentadas e cumprir os objetivos de investigação inicialmente estipulados, e também como forma de contribuir para a bibliografia científica sobre a utilização das social media na viagem turística, o presente estudo atua com dados primários que permitem atualizar alguns dos dados secundários recolhidos de outros autores e, ao mesmo tempo, apurar novas tendências no comportamento dos turistas nesta matéria.

Deste modo, optou-se por uma análise quantitativa, tendo sido implementado um inquérito feito à população residente em Portugal que tenha realizado, pelo menos, uma viagem turística nos anos 2014 e/ou 2015.

Tabela 2. Ficha técnica da amostra

\begin{tabular}{ll}
\hline Universo & Turistas portugueses que viajaram nos anos 2014 ou 2015 \\
\hline Tamanho da amostra & 250 questionários válidos \\
\hline Método de obtenção de dados & Inquérito por via de questionário online \\
\hline Procedimento da amostra & Amostra por conveniência \\
\hline Aplicação do inquérito & 20 de junho de 2016 a 23 de julho de 2016 \\
\hline
\end{tabular}

\subsection{Questionário}

O questionário foi construído em torno de três temáticas principais: a caraterização do perfil turístico do inquirido, o levantamento dos hábitos de utilização das social media e perceções sobre as mesmas, e a caraterização demográfica do inquirido (ver Tabela 3 ).

No primeiro grupo do questionário, pretende-se caraterizar o inquirido de acordo com os seus hábitos de consumo turístico. O foco recai sobre as viagens turísticas realizadas nos anos 2014 e/ou 2015.

O segundo grupo do questionário foca-se no estudo do comportamento do inquirido nas social media, tanto durante a viagem turística como no dia a dia. Simultaneamente, é averiguada a perceção que o inquirido tem sobre as social media e sobre a utilização das mesmas durante a viagem turística. Esta secção é o ponto central do presente estudo e os resultados alimentam a maioria das conclusões da investigação. As questões nesta secção foram concebidas, em parte, com base no estudo realizado por Fotis (2015), que construiu o modelo do processo de viagem habilitada pelas social media (Fotis, 2015: 293), criado com base num estudo qualitativo. Deste modo, pretende-se, essencialmente, validar e atualizar as conclusões de Fotis (2015), cruzando os seus resultados com os obtidos numa análise quantitativa. Assim, foram testadas as motivações identificadas pelo autor que levam à autoexpressão durante e após a viagem turística e atribuídos graus de influência diferentes aos fatores, consoante o peso que estes têm na motivação para a autoexpressão.

Esta secção do questionário divide-se em três partes: (1) Internet e social media em geral; (2) redes sociais; e (3) websites de reviews. A divisão surge como forma de tornar esta secção 
(essencial para o estudo) mais intuitiva, tanto para o inquirido, como para o investigador, no momento de análise dos dados. Será importante reparar que as redes sociais selecionadas para este estudo foram o Facebook e o Instagram (escolha motivada pela grande abrangência destas redes e pela sua adequação à partilha de conteúdos turísticos) e os websites de reviews nomeados foram o TripAdvisor (por ser de caráter generalista no turismo e ter uma grande base de utilizadores), o Booking (pelo foco no alojamento) e o Zomato (pelo foco na restauração).

Da tabela que se segue, refira-se que as questões 3.1., 3.5. e 4.2. serão alvo de cruzamento com os dados apurados por Fotis (2015). Já as questões 3.3. e 3.4. servirão para investigações futuras, nomeadamente acerca da demografia dos turistas que geram conteúdos.

Tabela 3. Secções e questões do questionário

\begin{tabular}{|c|c|}
\hline \multicolumn{2}{|c|}{ Perfil turístico do inquirido } \\
\hline $\begin{array}{c}\text { 2.1./2.1.1./ } \\
2.2 .\end{array}$ & Número de viagens realizadas em 2014 e 2015 . \\
\hline $\begin{array}{l}2 \cdot 3 \cdot / 2 \cdot 3 \cdot 1 \cdot / \\
2 \cdot 4 \cdot / 2 \cdot 4 \cdot 1\end{array}$ & Destinos visitados em turismo em 2014 e 2015. \\
\hline 2.5 . & Principais motivações para viajar em 2014 e 2015. \\
\hline $2.6 . / 2.6 .1$ & $\begin{array}{l}\text { Número médio de acompanhantes nas viagens em } 2014 \text { e } 2015 \text { e grau de } \\
\text { relacionamento com os mesmos. }\end{array}$ \\
\hline 2.7 . & Meios utilizados para efetuar reservas para as viagens feitas em 2014 e 2015 . \\
\hline 2.8. & Meios de transporte utilizados nas viagens feitas em 2014 e 2015 . \\
\hline 2.9 . & Caraterísticas do destino mais valorizadas enquanto turista. \\
\hline \multicolumn{2}{|c|}{ Social media: perceções e hábitos de utilização } \\
\hline 3.1. & Perceção do turista acerca do acesso à Internet em viagem. \\
\hline 3.2. & $\begin{array}{l}\text { Grau de familiaridade do turista com as social media definidas para o estudo } \\
\text { (Facebook, Instagram, TripAdvisor, Booking e Zomato). }\end{array}$ \\
\hline $3 \cdot 3 \cdot / 3 \cdot 4$ & Frequência de utilização das social media no dia-a-dia e durante a viagem. \\
\hline 3.5 & $\begin{array}{l}\text { Utilização das social media para consulta de informação que apoie nos } \\
\text { processos de tomada de decisão durante a viagem turística. }\end{array}$ \\
\hline $.1 . / 5.1$. & $\begin{array}{l}\text { Em que momento costuma o inquirido utilizar as social media para gerar } \\
\text { conteúdos referentes à viagem turística (se durante ou após a viagem). }\end{array}$ \\
\hline 4.2. & $\begin{array}{l}\text { Principais motivações que levam a que o inquirido se expresse nas redes } \\
\text { sociais referindo-se à sua viagem turística. }\end{array}$ \\
\hline $4 \cdot 3 \cdot / 4 \cdot 4$ & Natureza e forma dos conteúdos gerados pelo turista nas redes sociais. \\
\hline $4 \cdot 5$. & Elementos que constam nos conteúdos gerados nas redes sociais. \\
\hline 5.2. & Natureza das avaliações feitas pelo turista em websites de reviews. \\
\hline \multicolumn{2}{|c|}{ Caraterização demográfica do inquirido } \\
\hline 6.1. & Género. \\
\hline 6.2. & Idade. \\
\hline $6 \cdot 3 \cdot / 6 \cdot 3 \cdot 1$ & País habitual de residência. \\
\hline 6.4 . & Situação profissional \\
\hline 6.5 & Número de anos de escolaridade completados com sucesso. \\
\hline 6.6. & Número de elementos do agregado familiar. \\
\hline 6.7. & Rendimento líquido médio mensal do agregado familiar. \\
\hline
\end{tabular}


Em relação às perguntas 4.3. e 4.4., é colocada a hipótese de os conteúdos gerados pelo turista nas redes sociais tenderem a ser, sobretudo, experiências muito positivas, como forma de validar o seu consumo turístico; esta hipótese será testada na análise de dados empíricos.

Quanto à pergunta 5.2., coloca-se a hipótese de as avaliações feitas nos websites de reviews tenderem a ser ou muito negativas ou muito positivas, como consequência das respetivas experiências, tão marcantes quanto positivas ou negativas. Tal como mencionado no parágrafo anterior, esta hipótese também será testada na análise de dados empíricos.

O último grupo do questionário recai sobre a caraterização demográfica do inquirido, recorrendo a questões com base nos dados apurados pela TNS Political \& Social (2013) e por Yoo, Lee e Gretzel (You et al., 2007; Yoo \& Gretzel, 2008a; Yoo \& Gretzel, 2008b; Yoo \& Gretzel, 2012).

\subsection{Amostra e procedimento}

O inquérito foi disseminado na Internet, sobretudo via Facebook, e a amostra construída por conveniência. Esta via de disseminação poderá representar uma limitação, visto implicar que os inquiridos que obtiveram conhecimento do inquérito via Facebook tenham uma interação favorável com esta plataforma e, como tal, possam ter, a priori, uma predisposição positiva para a utilização de redes sociais e/ou da Internet, em geral. Contudo, e em adição à disseminação orgânica via Facebook, o inquérito foi também remetido por e-mail às comunidades académicas da Universidade do Algarve e da Escola Superior de Hotelaria e Turismo do Estoril.

O inquérito fez-se em três línguas (português, inglês e francês) e decorreu entre os dias 20 de junho de 2016 e 23 de julho de 2016, somando um total de 335 questionários respondidos. Os dados foram, posteriormente, organizados e analisados com recurso ao software IBM SPSS Statistics 20.

Dos 335 inquiridos, 85 foram excluídos por não terem viajado nos anos 2014 nem 2015 e/ou por não serem residentes em Portugal. Como tal, a amostra em estudo compreende 250 indivíduos portugueses que realizaram pelo menos uma viagem turística em 2014 ou 2015.

Após a construção da base de dados, foi desenvolvido o estudo estatístico relativamente à caraterização do perfil de utilização das social media por parte dos turistas portugueses. Para tal, estudaram-se as respostas às diferentes variáveis recorrendo a análises estatísticas descritivas e, em certos casos, a tabulações cruzadas.

3.2.1. Caraterização demográfica da amostra - a caraterização demográfica da amostra, de acordo com o levantamento obtido do inquérito, mostra que cerca de $68 \%$ dos inquiridos são do género feminino, facto que poderá ser consequência da forte presença do inquérito no Facebook, onde algumas mulheres inquiridas terão contribuído notoriamente para a disseminação do questionário, partilhando-o com os seus contactos mais próximos, que, teoriza-se, tenderão a ser, também, do género feminino.

As idades da amostra encontram-se entre os 15 e os 71 anos, estando a média aproximada situada nos 39 anos. A maioria (60\%) dos inquiridos são empregados por conta de outrem, 38\% completaram 17 anos de escolaridade (equivalentes ao atual mestrado em 
Portugal), 33\% pertencem a um agregado familiar com 3 elementos e $49 \%$ recebem entre $1500 €$ e $3000 €$ líquidos por mês no agregado.

\section{Análise de dados empíricos}

\subsection{Social media}

4.1.1. Frequência de utilização das social media - a amostra foi inquirida em relação à frequência com que utiliza cada uma das cinco redes sociais nomeadas para o presente estudo, tanto no dia a dia como durante a viagem. Esta análise (ver Tabela 4.) apresenta a alteração nos hábitos de utilização destas plataformas aquando da viagem turística. Os resultados são medidos numa escala de 1 a 5 , em que 1 se traduz para "nunca" e 5 se traduz para "sempre".

De facto, verifica-se uma descida generalizada na frequência de utilização das social media quando em viagem. Esta descida é mais acentuada nas redes sociais, que sofrem um declínio de cerca de $17 \%$ na frequência de utilização. Já nos websites de reviews, provavelmente devido à sua associação ao turismo e à utilidade que prestam enquanto plataformas de apoio à decisão do consumidor, sofrem uma redução de apenas cerca de $13 \%$.

Tabela 4. Frequência de utilização das social media no dia a dia vs. durante a viagem

\begin{tabular}{ccc}
\hline Social media & No dia-a-dia & $\begin{array}{c}\text { Durante a } \\
\text { viagem }\end{array}$ \\
\hline Redes Sociais & 3,5 & $2,9(-17 \%)$ \\
Facebook & 4,4 & 3,6 \\
Instagram & 2,5 & 2,1 \\
\hline Websites de Reviews & 2,3 & $2,0(-13 \%)$ \\
TripAdvisor & 2,4 & 2,2 \\
Booking & 2,8 & 2,4 \\
Zomato & 1,6 & 1,4 \\
\hline
\end{tabular}

4.1.2. Motivações para a autoexpressão nas redes sociais - tendo como base as motivações que segundo Fotis (2015) levam a que os turistas se exprimam nas redes sociais durante a viagem, aplicou-se uma análise quantitativa, de modo a medir quais os fatores que mais influenciam a propensão para a autoexpressão dos turistas nas redes sociais (ver Tabela 5).

Os resultados indicam que as motivações mais proeminentes são a conveniência (média de 3,6 em 5), seguida do desejo de partilhar momentos felizes (média de 3,5 em 5). Em contraste, as motivações menos influentes são o show-off (média de 2,5 em 5) e o desejo de expressar sociabilidade (também com média de 2,5 em 5).

Estes resultados mostram uma influência predominante de fatores associados à experiência vivida. Por outras palavras, o que fará o turista partilhar a experiência nas redes sociais não está sobretudo ligado ao ambiente social em que este se insere, mas sim à qualidade da experiência vivida, que, se suficientemente inédita e positiva, desencadeará a geração de conteúdos. Simultaneamente, isto significa que a maioria dos conteúdos gerados por turistas na Internet se referirão a experiências únicas e felizes. 
4.1.3. Natureza dos conteúdos publicados nas social media - para este estudo, testaram-se as hipóteses de que os conteúdos partilhados nas redes sociais costumam refletir, sobretudo, experiências positivas e de que as avaliações feitas em websites de reviews se referem, maioritariamente, a experiências muito positivas ou muito negativas.

Os resultados (ver Tabela 5) confirmam que, nas redes sociais, os turistas tendem a publicar conteúdos sobretudo sobre experiências positivas ( $49 \%$ da amostra). Esta conclusão está em conformidade com o analisado no subcapítulo das motivações que levam à autoexpressão, no qual se apurou que o desejo de partilhar momentos felizes é o fator que mais origina a partilha de conteúdos em viagem turística.

Tabela 5. Fatores que levam à autoexpressão do turista durante ou após a viagem

\begin{tabular}{|c|c|c|c|c|c|c|c|}
\hline Fator & Média & 1 & 2 & 3 & 4 & 5 & NS/NR \\
\hline Conveniência & $3,6 / 5$ & $8 \%$ & $8 \%$ & $21 \%$ & $36 \%$ & $25 \%$ & $1 \%$ \\
\hline Show off & $2,5 / 5$ & $27 \%$ & $22 \%$ & $26 \%$ & $16 \%$ & $6 \%$ & $2 \%$ \\
\hline Partilhar experiências únicas & $3,2 / 5$ & $14 \%$ & $13 \%$ & $24 \%$ & $34 \%$ & $14 \%$ & $2 \%$ \\
\hline Convidar outros a viver a experiência & $2,9 / 5$ & $22 \%$ & $15 \%$ & $26 \%$ & $27 \%$ & $9 \%$ & $2 \%$ \\
\hline Partilhar momentos felizes & $3,5 / 5$ & $13 \%$ & $8 \%$ & $16 \%$ & $38 \%$ & $22 \%$ & $2 \%$ \\
\hline Expressar sociabilidade & $2,5 / 5$ & $32 \%$ & $15 \%$ & $29 \%$ & $17 \%$ & $6 \%$ & $2 \%$ \\
\hline
\end{tabular}

Ainda referente à Tabela 6., nos websites de reviews, as avaliações feitas são predominantemente positivas ou negativas (40\% da amostra), ou seja, os conteúdos são publicados sem influência da sua natureza. Isto será reflexo do desejo de avaliar objetivamente os serviços e produtos turísticos consumidos e indicará uma maior veracidade destas avaliações, dada a relativa imparcialidade das mesmas.

Tabela 6. Natureza dos conteúdos partilhados pela amostra nas social media

\begin{tabular}{lc}
\hline O que refletem os conteúdos & $\%$ \\
\hline Redes Sociais & $9 \%$ \\
Experiências muito positivas e/ou muito negativas & $0,4 \%$ \\
Experiências negativas & $49 \%$ \\
Experiências positivas & $15 \%$ \\
Experiências, independentemente da classificação & $24 \%$ \\
Não partilha conteúdos nas redes sociais & $2 \%$ \\
NS/NR & \\
Websites de Reviews & $10 \%$ \\
Avaliações muito positivas e/ou muito negativas & $0,4 \%$ \\
Avaliações negativas & $13 \%$ \\
Avaliações positivas & $40 \%$ \\
Avaliações, independentemente da classificação & $30 \%$ \\
Não publica avaliações em websites de reviews & $6 \%$ \\
NS/NR &
\end{tabular}


4.1.4. Forma dos conteúdos partilhados nas redes sociais - os conteúdos partilhados nas redes sociais podem assumir várias formas. A fim de se aprofundar o estudo do comportamento do turista nas redes sociais, analisou-se quais os formatos (ou tipos de publicação) mais utilizados pelos turistas ao gerar conteúdos referentes às suas viagens (ver Tabela 7).

Os resultados mostram uma clara maioria favorável à partilha de publicações com fotografias (média de 3,7 em 5), face a outros formatos. Estima-se que esta crescente preferência exista por consequência direta da generalizada melhoria de qualidade das câmaras fotográficas nos smartphones utilizados atualmente, bem como da facilidade cada vez mais maior em submeter ficheiros multimédia na Internet em viagem, resultante da abundância de locais e meios de acesso à Internet.

Tabela 7. Forma dos conteúdos partilhados nas redes sociais

\begin{tabular}{lccccccc}
\hline Fator & Média & 1 & 2 & 3 & 4 & 5 & $\mathbf{N S} / \mathbf{N R}$ \\
\hline Publicações com apenas texto & $\mathbf{1 , 9} / 5$ & $\mathbf{4 0} \%$ & $\mathbf{2 8} \%$ & $\mathbf{1 5} \%$ & $\mathbf{7 \%}$ & $\mathbf{1 \%}$ & $8 \%$ \\
\hline Fotografias & $3,7 / 5$ & $\mathbf{1 1} \%$ & $\mathbf{5} \%$ & $\mathbf{1 4} \%$ & $\mathbf{3 2} \%$ & $\mathbf{2 9} \%$ & $8 \%$ \\
\hline Vídeos & $\mathbf{1 , 9 / 5}$ & $\mathbf{4 4 \%}$ & $\mathbf{2 4} \%$ & $\mathbf{1 5 \%}$ & $\mathbf{6 \%}$ & $\mathbf{2 \%}$ & $8 \%$ \\
\hline Mensagens privadas & $2,9 / 5$ & $\mathbf{2 2} \%$ & $\mathbf{1 3} \%$ & $\mathbf{2 4} \%$ & $\mathbf{2 3} \%$ & $\mathbf{1 0} \%$ & $6 \%$ \\
\hline
\end{tabular}

Em contraste, a amostra indica que os conteúdos gerados em viagem raramente são em formato de vídeo (1,9 em 5). Supõe-se que este facto se deva à inconveniência de partilhar ficheiros de vídeo em vez de ficheiros de fotografia, visto que o seu tamanho acrescido dificulta o carregamento online. Porém, a tecnologia tem evoluído significativamente neste sentido, tanto do lado das social media, como do lado dos meios de acesso à Internet, pelo que se estima que o vídeo se tornará rapidamente num formato mais proeminente.

Quanto às publicações que consistem apenas em texto, estas são raramente utilizadas (média de 1,9 em 5). Estima-se que a impopularidade deste formato esteja ligada ao facto de este tipo de publicações poder não ser tão apelativo nem conseguir ilustrar tão eficazmente a experiência turística do indivíduo como uma imagem ou vídeo.

Outro formato utilizado é a partilha através de mensagens privadas para um contacto em específico ou para uma conversa de grupo, com uma média de 2,9 em 5. Teoriza-se que a partilha por mensagem privada seja efetuada ocasionalmente, complementando os restantes conteúdos criados com informação adicional, destinada apenas a um contacto ou grupo de contactos com quem o turista terá maior proximidade.

De uma forma geral, estas conclusões confirmam que a experiência turística está abundantemente representada nas redes sociais através de fotografias, dando aso a que os contactos de cada turista formem uma perceção visual do destino em causa, com base nas imagens partilhadas por outros consumidores. No próximo capítulo, serão identificados os elementos da experiência turística que mais frequentemente constam nestes conteúdos.

4.1.5. Elementos que constam nos conteúdos partilhados nas redes sociais - de entre a lista de elementos da experiência turística enumerados no questionário, a amostra selecionou 
aqueles que costuma representar e/ou mencionar nos conteúdos que partilha nas redes sociais.

Tabela 8. Elementos que constam nos conteúdos partilhados nas redes sociais pelo turista

\begin{tabular}{lc}
\hline Elemento & $\%$ \\
\hline Eu próprio & $56 \%$ \\
\hline As pessoas com quem viajo & $48 \%$ \\
\hline Pessoas residentes & $13 \%$ \\
\hline Outros turistas & $2 \%$ \\
\hline Património natural (paisagens, flores, animais, ...) & $70 \%$ \\
\hline Monumentos (mosteiros, castelos, estátuas, ....) & $68 \%$ \\
\hline Museus & $35 \%$ \\
\hline Costumes tradicionais (fado, festas tradicionais, ...) & $32 \%$ \\
\hline Jardins e/ou parques & $50 \%$ \\
\hline Atividades (roteiros e animação turística) & $32 \%$ \\
\hline Espaços culturais (bibliotecas, teatros, ...), desportivos (piscinas públicas, ...), & $34 \%$ \\
recreativos (estádios, casinos, ... ), ou de negócios (centros de congressos, ...) & $3 \%$ \\
\hline Eventos (desportivos, culturais e artísticos) & $33 \%$ \\
\hline Alojamento & $28 \%$ \\
\hline Restaurantes & $32 \%$ \\
\hline Transportes & $6 \%$ \\
\hline Bares e discotecas & $11 \%$ \\
\hline Centros comerciais & $4 \%$ \\
\hline
\end{tabular}

De acordo com as respostas da amostra (ver Tabela 8.), o património natural (70\%) e os monumentos (68\%) são os elementos da experiência turística que mais constam nos conteúdos gerados pelos turistas portugueses. Os jardins e/ou parques são outra atração com grande presença nas redes sociais (50\%), o que, em conjunto com o património natural e os monumentos, compõe os três atrativos mais representados pelos turistas. Por outras palavras, quando um turista experiencia um destes três elementos, existe uma probabilidade de $50 \%$ a $70 \%$ (dependendo do elemento em questão) de este vir a criar conteúdos nas redes sociais nos quais está representado o elemento experienciado.

"Eu próprio" e "As pessoas com quem viajo" também são amplamente representados nas redes sociais (cerca de $56 \%$ e 48\%, respetivamente), sugerindo que o próprio turista está representado nos conteúdos que gera, em conjunto com outros elementos. Estima-se que, sobretudo no caso das fotografias e vídeos, o desejo de aparecer representado surge com a intenção de documentar a presença do indivíduo em determinado local ou atividade, bem como de, mais tarde, facilitar a recordação da experiência. Os elementos que a amostra menos representa nas redes sociais são "Outros turistas" (2\%), "Centros comerciais" (4\%) e "Transportes" (6\%). 


\section{Conclusão}

A literatura indica que os conteúdos gerados pelos turistas na Internet compreendem uma porção cada vez maior dos conteúdos de informação turística online. Devido a esta abundância, a Internet tornou-se numa fonte de informação extremamente valiosa para os turistas, tanto na fase de planeamento como durante a própria viagem.

No caso das social media, a presença de UGC é um elemento basilar destas plataformas. Como tal, dado o franco crescimento no número de utilizadores das social media, os comentários, opiniões e experiências partilhadas por turistas representam um contributo substancial para a informação turística online, valorizado pelo facto de os testemunhos de outros consumidores serem a fonte de informação preferida pelos turistas para apoio à tomada de decisão durante todas as etapas da viagem, conforme confirma a bibliografia científica.

Foi implementado um inquérito por via de questionário, permitindo que este estudo atue com dados primários em duas vertentes: por um lado, a validação e atualização dos dados secundários recolhidos de outros autores e, por outro, o apuramento de tendências no comportamento dos turistas nesta matéria. Este inquérito possibilitou o estudo dos comportamentos e hábitos de consumo turístico e utilização das social media em viagem dos turistas portugueses que viajaram nos anos 2014 e/ou 2015.

Os resultados indicam que os turistas portugueses têm uma perceção favorável acerca do uso da Internet em viagem e que se demonstram predispostos a utilizar as social media em viagem, ainda que se verifique uma descida na frequência de utilização em cerca de $17 \%$ nas redes sociais e $13 \%$ nos websites de reviews comparativamente ao dia a dia.

A revisão de literatura aborda os estudos de Fotis (2015), nos quais o autor identifica as principais motivações para a autoexpressão nas redes sociais, nomeadamente, a conveniência das redes sociais como plataforma de comunicação e os desejos de se vangloriar, de partilhar experiências únicas, de convidar outros a viver as experiências vividas pelo indivíduo, de partilhar momentos felizes e de expressar sociabilidade. No presente estudo, concluiu-se que, destas motivações, aquelas que mais influenciam os turistas são a conveniência e as motivações ligadas à qualidade da experiência; por outro lado, as motivações relativas ao ambiente social em que o indivíduo se insere não influenciam tanto os turistas portugueses. Em suma, as experiências únicas e felizes são as mais frequentemente partilhadas nas redes sociais.

Quando os turistas portugueses partilham conteúdos nas redes sociais, os elementos que mais frequentemente são mencionados ou representados são (para além de eles próprios e as pessoas com quem viajam) o património natural do destino, os monumentos e os parques/jardins. Por outras palavras, quando um turista que tipicamente partilha a sua viagem nas redes sociais experiencia qualquer um destes três últimos elementos, existe uma forte probabilidade de essa experiência motivar a geração de conteúdos.

Ainda nas redes sociais, os conteúdos mais partilhados nestas plataformas são fotografias sobre experiências positivas. Já nos websites de reviews, os conteúdos surgem independentemente da classificação dada à experiência, sendo que a maioria da amostra indicou que, quando escreve avaliações nos websites próprios, estas tanto são sobre experiências positivas, como negativas ou neutras.

O presente estudo resultou, então, numa análise singular (tanto quanto é dado a conhecer ao autor) do comportamento dos turistas portugueses nas social media, realizada 
no sentido de contribuir para a compreensão das motivações, do processo e das implicações referentes à geração de conteúdos pelo utilizador em turismo. Para além do levantamento e análise de dados empíricos, também a revisão da literatura representa um passo na consolidação e agregação da bibliografia científica nesta área que, dada a sua relativa juventude, não conta, ainda, com uma quantidade robusta de obras científicas e de autores.

\section{Referências}

Adjei, M. T., Noble, S. M. \& Noble, C. H. (2010). The influence of C2C communications in online brand communities on customer purchase behavior. Journal of the Academy of Marketing Science, 38(5), 634-653. doi: 10.1007/s11747-009-0178-5

Andrades, L. Dimanche, F., Prebensen, N., Chen, J. \& Uysal, M. (2014). Co-creation of experience value: A tourist behaviour approach. Creating experience value in tourism. In N.K. Prebensen, J.S. Chen \& M. Uysal (Eds.). Creating Experience Value in Tourism (pp. 95-112). London: CABI. doi: $10.1079 / 9781780643489.0095$

Buhalis, D. \& Law, R. (2008). Progress in information technology and tourism management: 20 years on and 10 years after the Internet-The state of eTourism research. Tourism Management, 29(4), 609-623. doi.org/10.1016/j.tourman.2008.01.005

Carrera, P., Chiu, C-Y., Pratipwattanawong, P., Chienwattanasuk, S., Ahmad, S.F.S. \& Murphy, J. (2008). My space, my friends, my customers. In P. O'Connor, W. Höpken \& U. Gretzel (Eds.), Information and Communication Technologies in Tourism 2008 (pp.94-105). New York: Springer Wein.

Carù, A. \& Cova, B. (2003). Revisiting consumption experience: A more humble but complete view of the concept. Marketing Theory, 3(2), 267-286. doi.org/10.1177/14705931030032004

Damian, R. (2014). Understanding digital marketing: Marketing strategies for engaging the digital generation. London: Kogan Page Publishers.

Facebook (2017). Company info. Disponivel em http://newsroom.fb.com/company-info/

Fotis, J. N. (2015). The use of social media and its impacts on consumer behaviour: The context of holiday travel. (Dissertação de doutoramento não publicada). Bournemouth University, Reino Unido.

Gentile, C., Spiller, N. \& Noci, G. (2007). How to sustain the customer experience: An overview of experience components that co-create value with the customer. European Management Journal, 25(5), 395-410. doi: 10.1016/j.emj.2007.08.005

Gretzel, U., Lee, Y-J., Tussyadiah, I. \& Fesenmaier, D. R. (2009, abril). Recounting tourism experiences: The role of new media. Comunicação apresentada na International Conference on Tourist Experiences: Meanings, Motivations, Behaviours. Preston, Reino Unido.

Gunn, C. (1988). Vacationscape: Designing tourist regions. New York: Van Nostrand Reinhold.

Huang, J. \& Hsu, C. H. C. (2009). The impact of customer-to-customer interaction on cruise experience and vacation satisfaction. Journal of Travel Research, 49(1), 79-92. doi.org/10.1177/0047287509336466

Instagram (2017). Stats. Disponível em https://www.instagram.com/press/

Kaplan, A. M. \& Haenlein, M. (2010). Users of the world, unite! The challenges and opportunities of social media. Business Horizons, 53(1), 59-68. doi:10.1016/j.bushor.2009.09.003

Kim, J-H. , Ritchie, R.B. \& Mccormick, B. (2012). Development of a scale to measure memorable tourism experiences. Journal of Travel Research, 51, 12-25. $10.1177 / 0047287510385467$.

Litvin, S.W., Goldsmith, R.E. \& Pan, B. (2008)._Electronic word-of-mouth in hospitality and tourism management. Tourism Management, 29(3), 458-468. doi.org/10.1016/j.tourman.2007.05.01

Mannell, R. C. \& Iso-Ahola, S. E. (1987). Psychological nature of leisure and tourism experience. Annals of Tourism Research, 14(3), 314-331. doi.org/10.1016/0160-7383(87)90105-8

Matos, N. (2014). The impacts of tourism experiences in the destination image. A marketing perspective. (Tese de doutoramento não publicada). Universidade do Algarve, Portugal.

Munar, A. M. \& Jacobsen, J. K. S. (2014). Motivations for sharing tourism experiences through social media. Tourism Management, 43, 46-54. doi.org/10.1016/j.tourman.2014.01.012

O'Connor, P. (2008). User-generated content and travel: A case study on Tripadvisor.com. Information and Communication Technologies in Tourism 2008, 47-58. 
Oh, H., Fiore, A. \& Jeoung, M. (2007). Measuring experience economy concepts: Tourism applications. Journal of Travel Research, 46(2), 119-132. doi.org/10.1177/0047287507304039

Pan, B., MacLaurin, T. \& Crotts, J.C. (2007). Travel blogs and the implications for destination marketing. Journal of Travel Research, 46(1), 35-45. doi.org/10.1177/0047287507302378

Pine, B. J. \& Gilmore, J. H. (1998). Welcome to the experience economy. Harvard Business Review, 76(4), 97-105.

Pine, B. J. \& Gilmore, J. H. (2011). The experience economy. Boston: Harvard Business School Press.

Quan, S. \& Wang, N. (2004). Towards a structural model of the tourist experience: An illustration from food experiences in tourism. Tourism Management, 25(3), 297-305. doi:10.1016/s02615177(03)00130-4.

TNS Political \& Social (2013). Attitudes of Europeans towards tourism. Disponível em: http://ec.europa.eu/public_opinion/flash/fl_370_en.pdf

Tung, V. \& Ritchie, J. (2011). Exploring the essence of memorable tourism experiences. Annals of Tourism Research, 38(4), 1367-1386. doi: 10.1016/j.annals.2011.03.009

Uriely, N. (2005). The tourist experience. Conceptual developments. Annals of Tourism Research, 32(1), 199-216. doi: 10.1016/j.annals.2004.07.008

Xiang, Z. \& Gretzel, U. (2010). Role of social media in online travel information search. Tourism Management, 31(2), 179-188. doi.org/10.1016/j.tourman.2009.02.016

Yoo, K. H. \& Gretzel, U. (2008a). Use and impact of online travel reviews. Information and Communication Technologies in Tourism 2008, 35-46. doi.org/10.1007/978-3-211-77280-5_4

Yoo, K. H. \& Gretzel, U. (2008b, janeiro). Understanding differences between online travel review writers and non-writers. Comunicação apresentada na 13th Annual Graduate Education and Student Research Conference in Hospitality and Tourism, Orlando, Florida.

Yoo, K. H. \& Gretzel, U. (2008c). What motivates consumers to write online travel reviews? Information Technology \& Tourism, 10(4), 283-295. doi.org/10.3727/109830508788403114

Yoo, K. H. \& Gretzel, U. (2010). Antecedents and impacts of trust in travel-related consumer generated $\begin{array}{lllll}\text { media. Information Technology \& } & \text { 139-152. }\end{array}$ doi: $10.3727 / 109830510 \times 12887971002701$

Yoo, K. H. \& Gretzel, U. (2011). Influence of personality on travel-related consumer-generated media creation. Computers in Human Behavior, 27(2), 609-621. doi.org/10.1016/j.chb.2010.05.002

Yoo, K. \& Gretzel, U. (2012). Use and creation of social media by travellers. In M. Sigala, E. Christou \& U. Gretzel (Eds.), Social media in travel, tourism and hospitality (pp. 189-205). Reino Unido: Ashgate.

Yoo, K. H., Lee, K. S. \& Gretzel, U. (2007, Janeiro). The role of source characteristics in eWOM: What makes online travel reviewers credible and likeable? In M. Sigala, L. Mich, J. Murphy \& A. Frew (Eds), Proceedings of the 14th International ENTER Conference (pp. 23-34). Ljubljana, Slovenia.

Yoo, K. H., Lee, Y., Gretzel, U. \& Fesenmaier, D. R. (2009). Trust in travel-related consumer generated media. Information and Communication Technologies in Tourism 2009, 49-59. doi.org/10.1007/978-3-211-93971-0_5

NUNO M.B. ANTUNES é licenciado em Gestão do Lazer e Animação Turística pela Escola Superior de Hotelaria e Turismo de Estoril, e terminou o mestrado em Marketing Turístico, com 18 valores, na Escola Superior de Gestão, Hotelaria e Turismo da Universidade do Algarve, tendo desenvolvido a tese de mestrado sobre a partilha de conteúdos turísticos nas redes sociais e websites de avaliações. A sua primeira publicação foi o artigo “Click Bait: You Won’t Believe What Happens Next!”, publicado internacionalmente na revista Fronteiras: Journal of Social, Technological and Environmental Science. Endereço institucional: Escola Superior de Gestão, Hotelaria e Turismo da Universidade do Algarve, Campus da Penha, 8005-139 Faro, Portugal.

CÉLIA M. Q. RAMOS é doutorada em Métodos Quantitativos aplicados à Economia e à Gestão, na especialidade de Econometria, pela Universidade do Algarve. É Mestre em Engenharia Eletrotécnica e de Computadores pelo Instituto Superior Técnico e licenciada em Engenharia Informática pela Universidade de Coimbra. É Professora na ESGHT da Universidade do Algarve, desde 1992, na área científica dos Sistemas e Tecnologias da Informação. É membro integrado do CIEO da Universidade do 
Algarve. As suas áreas de investigação são Sistemas de Informação, Business Intelligence, Big Data, Turismo Eletrónico, Marketing Digital e Modelos de Dados em Painel. Tem publicado nas áreas dos sistemas de Informação e do turismo. É revisora de revistas a nível internacional e participou em vários projetos financiados. Endereço institucional: Escola Superior de Gestão, Hotelaria e Turismo da Universidade do Algarve, Campus da Penha, 8005-139 Faro, Portugal.

CARLOS MANUEL RAMOS DE SOUSA é licenciado em Informática de Gestão pelo Instituto Superior de Línguas e Administração (1990), mestre em Ciências Económicas e Empresarias (2001) e doutor em Ciências Económicas e Empresariais pela Universidade de Huelva (2007). É Professor Adjunto na Escola Superior de Gestão, Hotelaria e Turismo da Universidade do Algarve na área científica dos Sistemas e Tecnologias da Informação, desde 1991, onde exerce a sua atividade de docência na área dos sistemas e tecnologias da informação e comunicação. As suas áreas de interesse e atividade letivas relacionamse com os Sistemas e Tecnologias da Informação nas organizações, Informática Aplicada ao Turismo, Distribuição Eletrónica no Turismo, Customer Relationship Management e o Marketing Digital. Endereço institucional: Escola Superior de Gestão, Hotelaria e Turismo da Universidade do Algarve, Campus da Penha, 8005-139 Faro, Portugal.

Submetido em 12 novembro 2017

Aceite em 5 março 2018 